\begin{tabular}{|c|l|}
\hline Title & A new practical method for prediction of geomechanical failure time \\
\hline Author(s) & Mufundirwa, A.; Fujii, Y.; Kodama, J. \\
\hline Citation & $\begin{array}{l}\text { International Journal of Rock Mechanics and Mining Sciences, 47(7), 1079-1090 } \\
\text { https://doi.org/10.1016/.ijrmms.2010.07.001 }\end{array}$ \\
\hline Issue Date & 2010 -10 \\
\hline Doc URL & http://hdl.handle.net/2115/44025 \\
\hline Type & article (author version) \\
\hline File Information & Azania2010.pdf \\
\hline
\end{tabular}

Instructions for use 


\title{
A new practical method for prediction of geomechanical failure-time
}

\author{
A. Mufundirwa*, Y. Fujii, J. Kodama \\ Graduate School of Engineering, Hokkaido University, N13 W8, Kita-ku, Sapporo 060-8628, Japan \\ ('Corresponding author. Tel/Fax: +81 11706 6299.) \\ E-mail address: azania@ rock.eng.hokudai.ac.jp (A. Mufundirwa). \\ E-mail address: fujii6299@eng.hokudai.ac.jp (Y. Fujii).
}

\begin{abstract}
Can we predict failure-time of geo-hazards? This question, poses a traditional rock mechanics problem. It is a challenge to date in the rock mechanics field to precisely predict failure-time of geo-hazards, and geo-hazards still pose major threat to life and major loss in terms of economics. The focal point of our research is to predict failure-time of geo-hazards. Firstly, we evaluated the validity of the INVerse-velocity (INV) method to predict failure-time of rock mass and landslides. And as a merit, the method utilizes rates of displacement $(\mathrm{d} u / \mathrm{d} t)$ or strain $(\mathrm{d} \varepsilon / \mathrm{d} t)$ to predict the actual failure-time $\left(T_{\mathrm{f}}\right)$, so the value of total displacement or strain before "failure" is not crucial. Secondly, we developed a new method for computing failure-time predictions based on the SLOpe (gradient) to predict $T_{\mathrm{f}}$, termed the SLO method, which will be described in detail in the paper. And in tally, a simple conceptualised model representing "safe" and "unsafe" predictions was proposed.

To validate these hypotheses, prediction of rock mass failure, Asamushi and Vaiont landslides (in situ studies) was conducted. Furthermore, laboratory conditions were incorporated into the research, which are: (i) predictions using circumferential strain $\varepsilon_{\mathrm{c}}$ and axial strain $\varepsilon_{\mathrm{a}}$ from uniaxial compression creep test on Shikotsu welded tuff (SWT); and (ii) predictions of failure-time for Inada granite under Brazilian creep tests. It was realized that SLO method is better than the INV method; SLO gave safe predictions in all the cases. In contrast, INV tends to give unsafe predictions (predicted failure-time $T_{\mathrm{fp}}>T_{\mathrm{f}}$ ). Our findings reveal that predictions using $\varepsilon_{\mathrm{c}}$ are better than using $\varepsilon_{\mathrm{a}}$ for SWT, and notably, given failure with very short tertiary creep, the methods tend to show limited reliability. However, SLO method could find extensive application in predicting failure-time of geo-hazards, for instance, roof wall failure in mines etc.; this method is promising in reducing fatalities and damage to property which industry and society still face at present.
\end{abstract}

Keywords: Rock mass failure; Landslide; Failure-time prediction; Displacement rate; Strain rate

\section{Introduction}

The issue of predictability of landslides and rock slope failures, which are major geo-hazards, is of great concern. In the geotechnical field, structures are monitored to ascertain their stability, but the question, "When is geomechanical failure going to occur?" is still an issue. Various monitoring equipment and devices such as Global Positioning System (GPS), Slope Stability Radar (SSR), extensometers, survey stations, and others are used yet somehow "failure" still occurs unanticipated. Needless to mention, monitoring the behaviour of landslides and rock slopes is an important aspect to mitigate failure or accidents, and is vital in successfully forecasting the time of slope failure.

In a broad sense, previous research had been conducted in the prediction of landslides, rock mass and rock slope failures fundamentally using displacement, strain, or deformation rates. 
In particular, much attention has been focused on accelerating creep, because of the increasing rock fabric damage prior to "failure." Extensively, it is reported that accelerating trends prior to slope failure utilize deformation rates [1-11]. Although there is no universally accepted equation to describe accelerating creep rates in geomaterials, more often, previous predictions in the field of rock mechanics have used empirical equations based on exponential laws, power laws, etc. [2-10]. In retrospect, Voight's accelerating creep theory utilizes values of dimensionless parameters ( $A$ and $\alpha$ ) on displacement ratetime and inverse rate plot to predict failure-time associated with the assumed failure rate $[6,7]$. He concluded that the value of $\alpha$ ranges generally from 1.7-2.2 and influences the curvature of the inverse rate plots, and $A$ is a positive constant. Saito and Uezawa [2] and Saito [3,4] suggested a relationship between time to creep rupture and strain rate. They found that time to creep rupture was inversely proportional to the strain rate and independent of the soil type. Fukuzono [10] used inverse-velocity to predict failure-time for sand slopes based on laboratory test. He presented three types of inverse-velocity plots fitted to laboratory data (convex, linear and concave), and finally concluded that, a linear fit through the inverse-velocity against time data provided a reasonable estimate of failure-time, shortly before failure. Recently, Rose and Hungr [11] attempted to forecast potential rock slope failure in mines using the inverse-velocity method. They recommended the use of linear fits for prediction of anticipated displacement and commended Fukuzono's inverse-velocity as a powerful tool for estimating the timing of the failure process. Fujii et al. [12] discusses prediction of rock specimen failure under various stress states using circumferential strain in the laboratory. In their conclusion, they said it would be possible to predict rock failure by simply comparing the critical tensile strain values from constant strain rate tests.

From a different perspective, Crosta and Agliardi [8] discuss about alert velocity threshold levels. They developed a method to forecast failure of deep-seated, creeping-type rock slides based on Voight's semi-empirical time dependent failure criterion. The method utilizes Voight's model to get "characteristic velocity curves" which resembles the nonlinear time-dependent behaviour of rock mass towards failure.
According to their findings, velocity curves describe "how fast" a rock slide will move at a given time before failure, with or without knowing when the failure will exactly occur. As a positive development, they defined 30,15 and 7-days alert velocity thresholds, which are currently in use in Regione Lombardia, Italy. In a similar approach, Cruden and Masoumzadeh [9] proposed three accelerating creep stages to enable prediction of the critical slide velocity so as to begin evacuation of pit personnel and equipment before failure. Results from their study in an open-pit coal mine, yielded threshold velocities of $0.02,0.1$ and $0.5 \mathrm{~mm} / \mathrm{min}$ for the three corresponding accelerating creep stages. As a limitation, they highlighted that these threshold velocities could be applicable to slope movement similar to those found in 51-B-2 pit. Likewise, some researchers suggested a critical slide velocity of $0.5 \mathrm{~mm} / \mathrm{min}$ that should trigger evacuation of pit personnel and equipment under a moving mass, hours before failure [13,14]. In addition, Zavodni and Broadbent [15] reported displacement rates ranging from $0.04-1.04 \mathrm{~mm} / \mathrm{min}$ at the time of failure.

We are not attempting to give a review of all methods proposed in attempts to predict geomechanical failure-time, but as we have learnt from previous cases presented hereinabove, most of them utilizes the accelerating creep theory and are somewhat biased towards site-specific conditions. Factually, it is crucial to appreciate that, in reality, some slope failures are largely dominated by processes or mechanisms that are not effected by creep (e.g., structural failures). Therefore, with the aid of real-time slope monitoring systems, there is a need to focus on simple and quick methods that are extensive in application and with minimal sensitivity to different lithology, sizes/volumes of failure and more importantly to failure mechanisms. With this in mind, we are proposing a new prediction method (Eq. 3) that utilizes the divergence phenomenon of measured displacement or strain prior "failure," so that we can predict geomechanical failure-time irrespective of failure mechanism, lithology and any other parameters.

In a preview, failure-times of case histories, which include rock mass failure, Asamushi and Vaiont landslides were predicted, and subsequently evaluated for reliability. 
Furthermore, using the same principles, predictions using circumferential strain $\varepsilon_{\mathrm{c}}$ and axial strain $\varepsilon_{\mathrm{a}}$ on Shikotsu welded tuff (SWT) under uniaxial compression creep tests were conducted. And lastly, predictions of failure-time for Inada granite under Brazilian creep tests are presented.

\section{Prediction Methods}

From our discussion in Section 1, we have observed that most of the prediction methods developed and/or currently in use, utilize the accelerating creep theory that is largely dependent on deformation rates. And as a limitation, these methods are somewhat limited to site-specific conditions. Hence there is a need, to develop simple, quick and reliable prediction methods that can find extensive application under different failure mechanisms, geometrical and hydrogeological complexity, etc. However, to develop such methods with a broad range of application, it would be reasonable to assume that accelerating displacements or strains of slopes prior to failure are analogous to the terminal phase in tertiary creep. Under this assumption, we could possibly encompass prediction of failure-time for diverse geomechanical failures caused by structural failures, creep and other precursory failure mechanism.

To begin with, in our endeavour to address the abovementioned issues, we adopted Eq. (1) proposed by Fukui and Okubo [16] representing strain divergence in the terminal phase of creep failure in rocks.

$\varepsilon=-B \log \left(T_{\mathrm{f}}-t\right)+C$,

where $\varepsilon$ : strain, $t$ : time, $T_{\mathrm{f}}$ : failure time, $T_{\mathrm{f}}-t$ : life expectancy, $B$ and $C$ : constants. In our derivations, we substituted displacement $u$ instead of strain $\varepsilon$ and differentiated both sides of Eq. (1) with respect to time $t$ :

$\frac{\mathrm{d} u}{\mathrm{~d} t}=\frac{B}{T_{\mathrm{f}}-t}$,

where $(\mathrm{d} u / \mathrm{d} t)$ is the displacement rate. Re-arranging Eq. (2), we get Eqs. (3) and (4). This was done so that we could increase our chances of developing a suitable alternative prediction method. $t \frac{\mathrm{d} u}{\mathrm{~d} t}=T_{\mathrm{f}} \frac{\mathrm{d} u}{\mathrm{~d} t}-B$

$\frac{\mathrm{d} t}{\mathrm{~d} u}=-\frac{t-T_{\mathrm{f}}}{B}$.

Using simple arithmetic, $T_{\mathrm{f}}$ is evaluated as the slope of $t(\mathrm{~d} u / \mathrm{d} t)-\mathrm{d} u / \mathrm{d} t$ curve for Eq. (3); this is our newly developed method termed the SLO. And in the other method $T_{\mathrm{f}}$ is evaluated as the $x$-intercept of $(\mathrm{d} t / \mathrm{d} u-t)$ curve for Eq. (4). From our derivation, the latter is called the INV method, conventionally inverse-velocity method [10]. Apparently, $t$ can be measured from an arbitrary initial time.

Reasonably, using measured displacement or strain; we can compute deformation rates (displacement or strain rate) using the data filtering method Eq. (5), so as to allow for smoothing of short-term deformation deviations that could be insignificant or cause "false" alarms. The data filtering method consists of using the $n$th observation (sampling value) to calculate the rate:

$\left(\frac{\mathrm{d} u}{\mathrm{~d} t}\right)_{i}=\frac{u_{i}-u_{i-n}}{t_{i}-t_{i-n}}(i=n+1, \mathrm{n}+2, \ldots, m)$,

where $(\mathrm{d} u / \mathrm{d} t)_{i}$ are the computed displacement rate points, $t_{\mathrm{m}}$ and $u_{\mathrm{m}}$ are the time and displacement at the instant of prediction, respectively [11]. Sampling value, $n$, was selected so as to yield positive rates of displacement or strain only.

\subsection{Concept of "safe" and "unsafe" predictions}

To begin with, we will describe a simple concept to classify predicted failure-times yielded from Eqs. (3) and (4) termed the SLO and INV, respectively. Fig. 1 shows an annotated diagram for the concept of "safe" and "unsafe" predictions. $T_{\mathrm{f}}$ is actual failure-time, $T_{\mathrm{fp}}$ is the predicted failure-time, and $t_{\mathrm{m}}$ is the time at each instant of predicting failure-time. The $y$-axis represents predicted life expectancy at $t_{\mathrm{m}}\left(T_{\mathrm{fp}}-t_{\mathrm{m}}\right)$. The line $\mathrm{AB}$ represents the actual life expectancy. $T_{\mathrm{fp}}$ equals $T_{\mathrm{f}}$ if $T_{\mathrm{fp}}$ at $t_{\mathrm{m}}$ is located on the line AB (a). And if $T_{\mathrm{fp}}$ at $t_{\mathrm{m}}$ is located above the line $\mathrm{AB}(\mathrm{b})$, the prediction is unsafe $\left(T_{\mathrm{fp}}>T_{\mathrm{f}}\right)$. This physically means that failure will begin before prediction $T_{\mathrm{fp}}$ and people cannot evacuate. Furthermore, if $T_{\mathrm{fp}}$ at $t_{\mathrm{m}}$ is located in the region $\mathrm{OAB}(\mathrm{c})$, the prediction is safe. And this allows for 
evacuation or emergency preparedness before any "failure" occurs. On the other hand, if $T_{\mathrm{fp}}$ at $t_{\mathrm{m}}$ is located below the line OB (d), failure should have occurred before $t_{\mathrm{m}}$ and the prediction is meaningless.

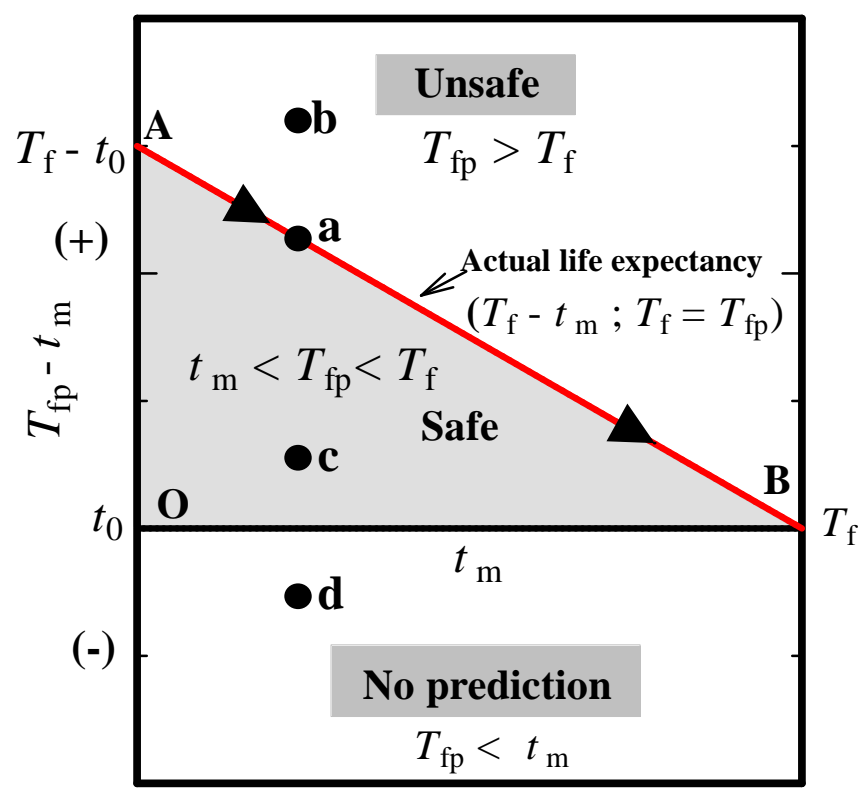

Fig. 1. A simple conceptual model representing predicted life expectancy $\left(T_{\mathrm{fp}}-\right.$ $t_{\mathrm{m}}$ ) as a function of $t_{\mathrm{m}}$ (time at instant of predicting) as failure-time $T_{\mathrm{f}}$ approaches. Note: $t_{0}$ is initial arbitrary time representing commencement of prediction and $T_{\mathrm{f}}-t_{0}$ is initial actual life expectancy.

\section{Case Histories in geomechanical failure}

In this section, we will present case histories used in our study, namely rock mass failure, Asamushi and Vaiont landslides.

\subsection{Rock mass failure in open-pit mine}

In this case study, rock mass failure $\left(500 \mathrm{~m}^{3}\right)$ occurred on a rock slope at a limestone mine in Japan (Fig. 2). Fortunately, no injuries or damage to property were reported. Geologically, it comprised of clayey limestone bands of varying thickness [17].

\subsubsection{Displacement trends}

Displacement for the rock mass movement was measured using a wire extensometer (Osashi Technos), the SLG-30 (inver wire-type) sensor and a NetLG-501 data logger at oneminute intervals. Fig. 3 illustrates the daily variations of relative displacement and precipitation over a 5-month period.

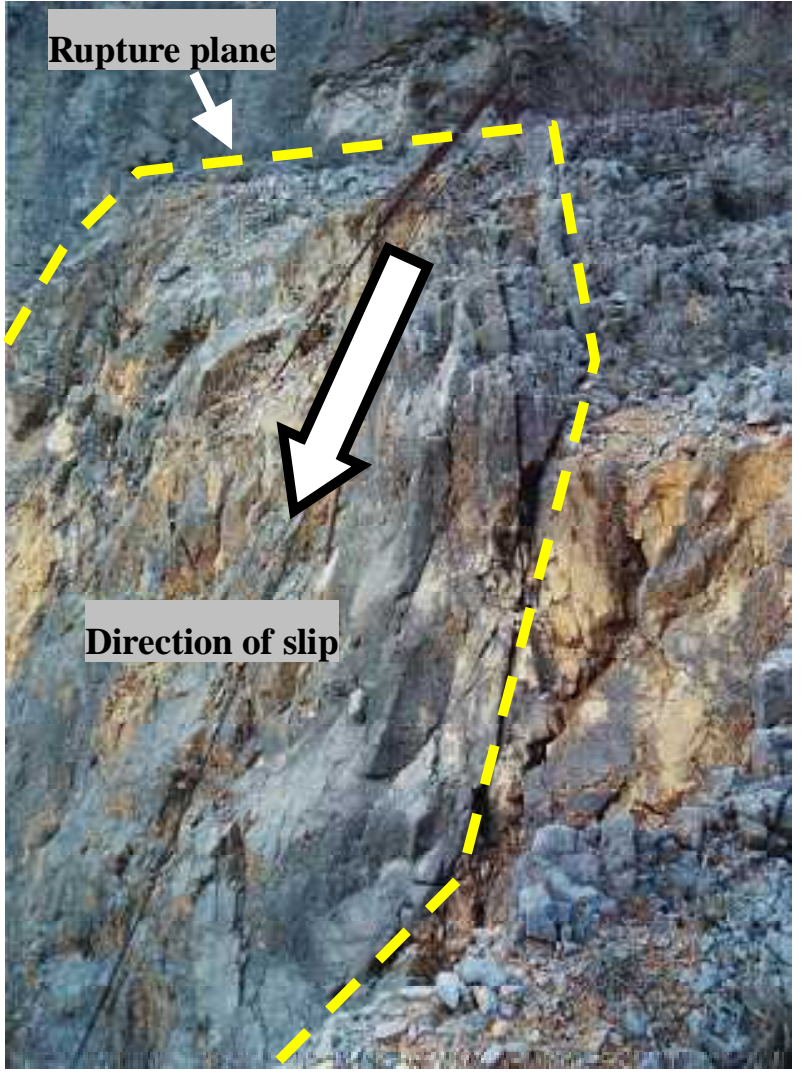

Fig. 2. Rock mass failure in an open-pit limestone mine, Japan (2007).

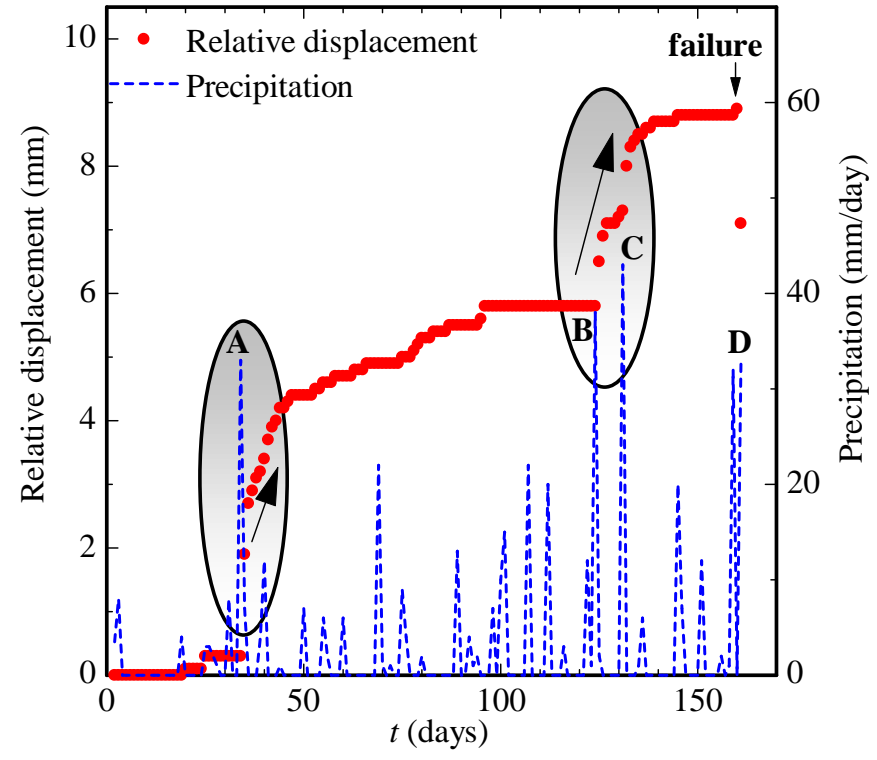

Fig. 3. Relative displacement (one-day average) and precipitation for over 5 months before the rock mass failure.

As evidenced, remarkable precipitation at points $\mathrm{A}, \mathrm{B}$ and $\mathrm{C}$ (33 mm, $38 \mathrm{~mm}$ and $43 \mathrm{~mm}$, respectively) caused corresponding steep trend changes in relative displacement 
a

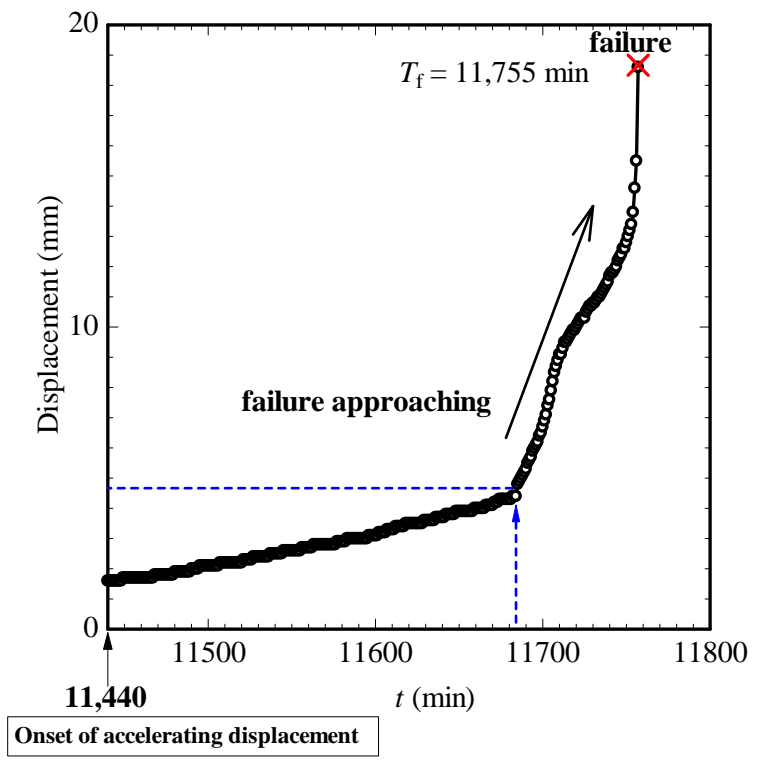

b

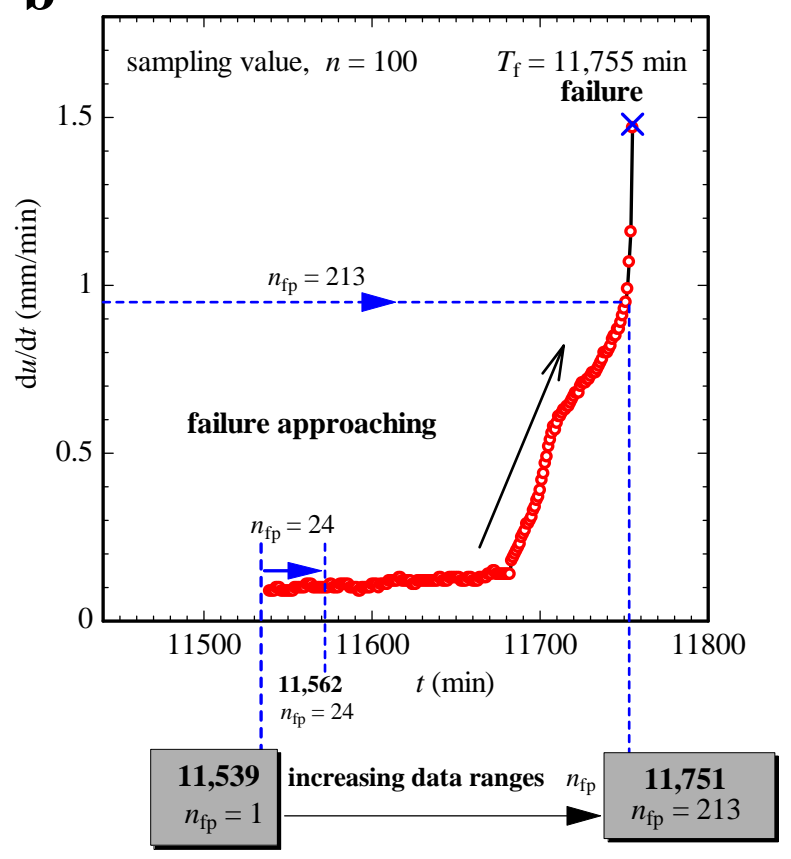

Fig. 4. (a) Displacement as a function of time $t, 5.25$ hours before rock mass failure (b) displacement rate as a function of time $t$.

(Fig. 3). At failure ( $\approx 158$ days) there was high precipitation (see Point D in Fig. 3). From observations, we can conclude that high precipitation and a rupture plane within the rock mass (Fig. 2) were the predominant factors that led to rock mass failure. And because of the large rupture plane, it is reasonable to assume that failure was triggered by structural complexity.

\subsubsection{Observational approach}

Since the rock mass was dominated by structural failure, using observation and sound judgement, we managed to estimate the onset of accelerating displacements similar to the terminal phase in tertiary creep. As a limitation, we acknowledge that it is difficult to locate precisely the boundary between steady and accelerating displacements in both structural failures and other mechanisms (e.g., creep) $[18,19]$.

During data collection, precise recording was done at 11,755 $\min \left(T_{\mathrm{f}}\right)$ prior to failure, and Fig. 4a shows displacement during the last stages of failure (June 2007). Using the observational approach, we estimated the onset of accelerating displacement at $t=11,440 \mathrm{~min}(u=1.6 \mathrm{~mm})$ as illustrated in Fig. 4a. Notably, displacement gradually increased until $t=11,682 \mathrm{~min}(u=4.6 \mathrm{~mm})$, and thereafter, displacement steeply increased towards failure, $T_{\mathrm{f}}=11,755$ $\min (u=18.6 \mathrm{~mm})$ as shown in Fig. 4a. The sudden increase in displacement towards failure was possibly due to the rupture plane within the rock mass (Fig. 2), triggering accelerating displacement, provided that, there were no other external conditions causing the displacement. The effects of blasting vibration are not significant, as "failure" occurred during postmining activities.

Later on, displacement rate was calculated using the data filtering method, Eq. (5) under $n=100$ (100 min), as in Fig. 4b, and displacement rates in the pre-failure range were 0.09-1.47 $\mathrm{mm} / \mathrm{min}$ (Fig. 4b). Zavodni and Broadbent [15] reported displacement rates ranging from $0.04-1.04 \mathrm{~mm} / \mathrm{min}$ at failure. As a general rule of thumb, Wyllie et al. [13] and MacRae [14] suggested a critical slide velocity of $0.5 \mathrm{~mm} / \mathrm{min}$ for the evacuation of pit personnel and equipment. From Fig. 4b, at velocities $\geq 0.14 \mathrm{~mm} / \mathrm{min}$, the curve was approaching failure. Hence, there is some element of agreement amongst these velocities as possible indicators of imminent failure. However, as a constraint, given the variable nature of rock masses, these velocities may not necessarily hold for all sizes and sorts of failure.

\subsection{Asamushi Landslide}

The $100,000 \mathrm{~m}^{3}$ landslide occurred at Asamushi at 22:12 in July 1966, on the Tohoku line, Japan, interrupting railroad 
$\mathbf{a}$

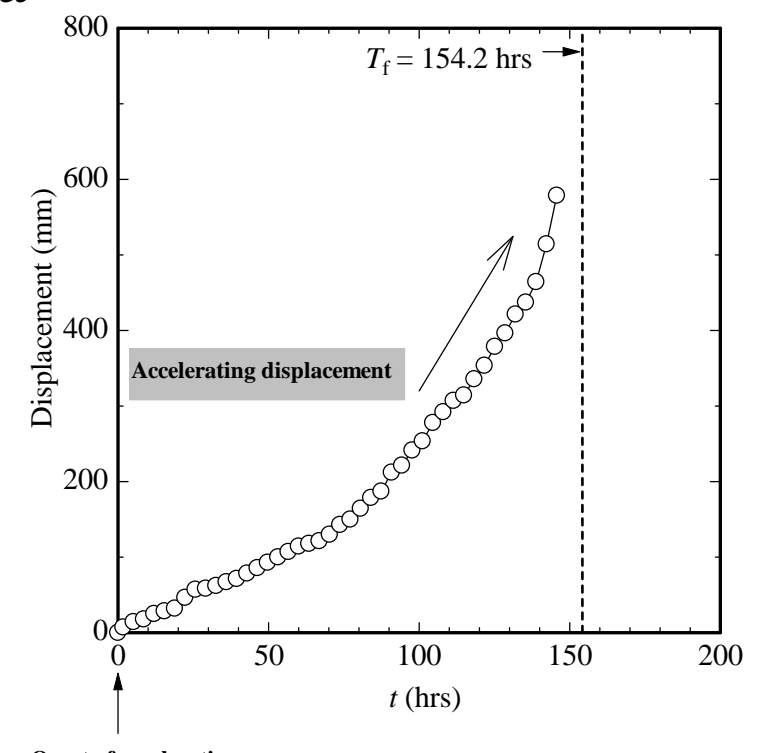

Onset of accelerating creep

b

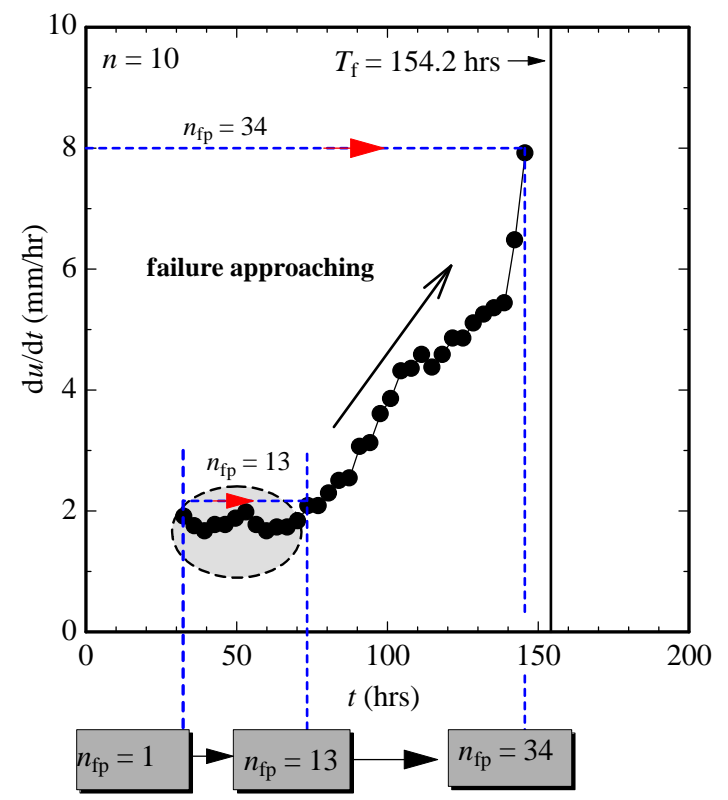

Fig. 5. (a) Displacement as a function of time $t$ towards failure $T_{\mathrm{f}}=154.2 \mathrm{hrs}$ for Asamushi landslide, Japan (b) displacement rate as a function of $t$ using $n=$ 10 (32.5 hrs) in Eq. (5), (data from [4]).

traffic for 26 days and burying $80 \mathrm{~m}$ length of track [4]. The geologic structure of the zone of landslide consisted of near surface joints in liparitic tuff.

\subsubsection{Trends}

An automatic recording device was used to measure landslide displacement in the last stages prior to failure. Displacement was only recorded in the tertiary creep range, $\mathbf{a}$

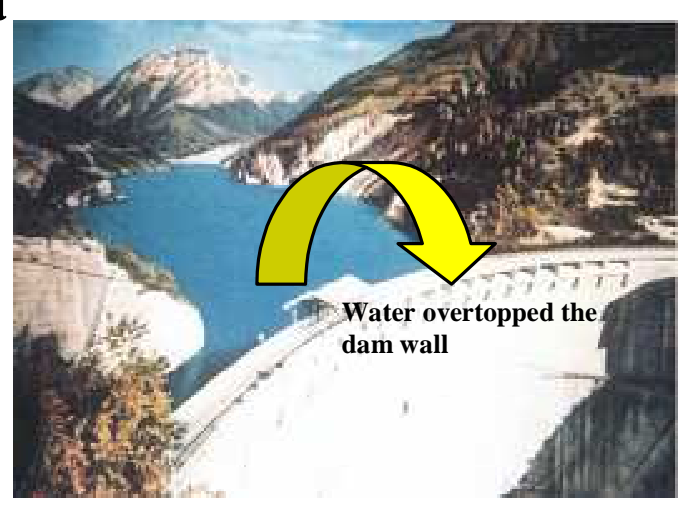

b

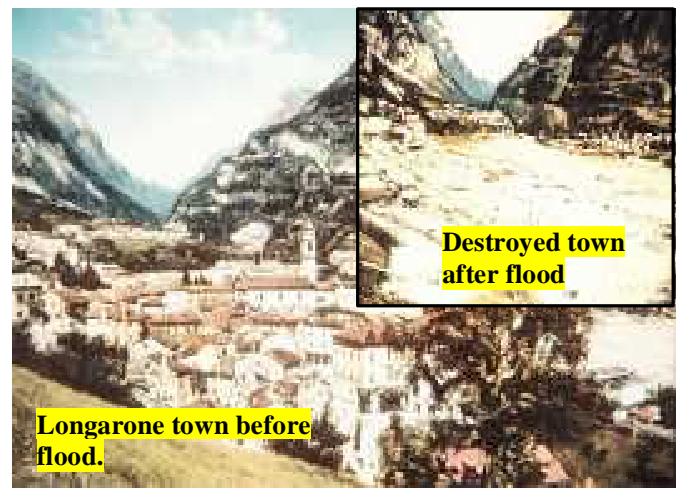

Fig. 6. Vaiont reservoir landslide disaster (a) Dam before landslide failure (b) Longarone town, before and after Mount Toc failure in October 1963 (pictures from [20]).

possibly due to late installation of the recording device [4]. With reference to Fig. 5a, displacement gradually increased as failure approached, from $t=0 \mathrm{~min}$ (assumed onset of accelerating creep). However, from 32-60 hrs velocities were cyclic but progressively increased towards failure (Fig. 5b).

\subsection{Vaiont Reservoir Landslide Disaster}

The catastrophic failure of approximately 270 million $\mathrm{m}^{3}$ occurred at 23:39 on 9 October 1963 in northeastern Italy [19]. The Vaiont canyon is located at $680 \mathrm{~m}$ above sea level. The landslide occurred on the southern slope of the Vaiont dam reservoir. A large sudden mass collapsed into the reservoir generating a wave that overtopped the dam. The dam wall collapsed and caused a flood that killed about 2,000 people and destroyed the town of Longarone downstream (Fig. 6). The failure process was controlled by external factors [11]. Geologically, it consisted of limestone and shale, which were 
$\mathbf{a}$

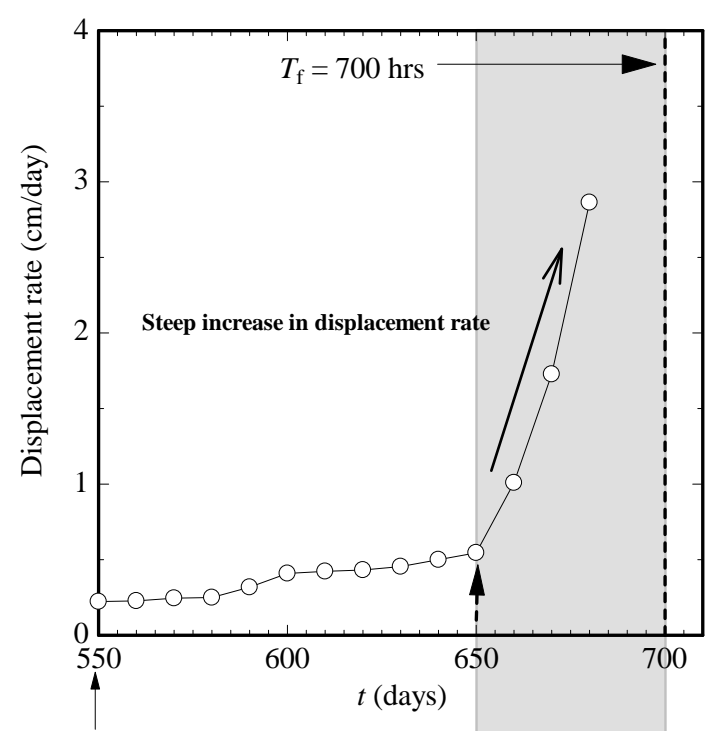

Onset of accelerating creep

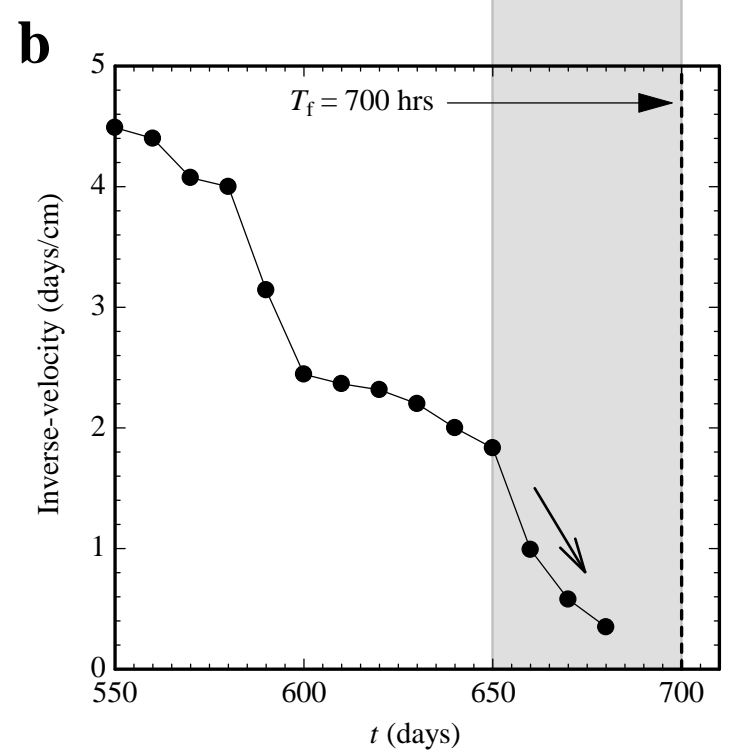

Fig. 7. Vaiont reservoir landslide disaster (a) Displacement rate during the last 150 days before failure. (b) Inverse-velocity versus time $t$ (data from [11]).

badly deformed and fractured. Generally, it is agreed that failure occurred along bands of clay within limestone [19]. Heavy rainfall shortly before the failure may also have contributed significantly to increase in pore pressure [11]. There was evidence of creep activity on the southern side of the canyon, and it increased as the level of reservoir rose. Various authors have presented different dynamics and kinematics behaviour of the Vaiont landslide [19]. $\mathbf{a}$

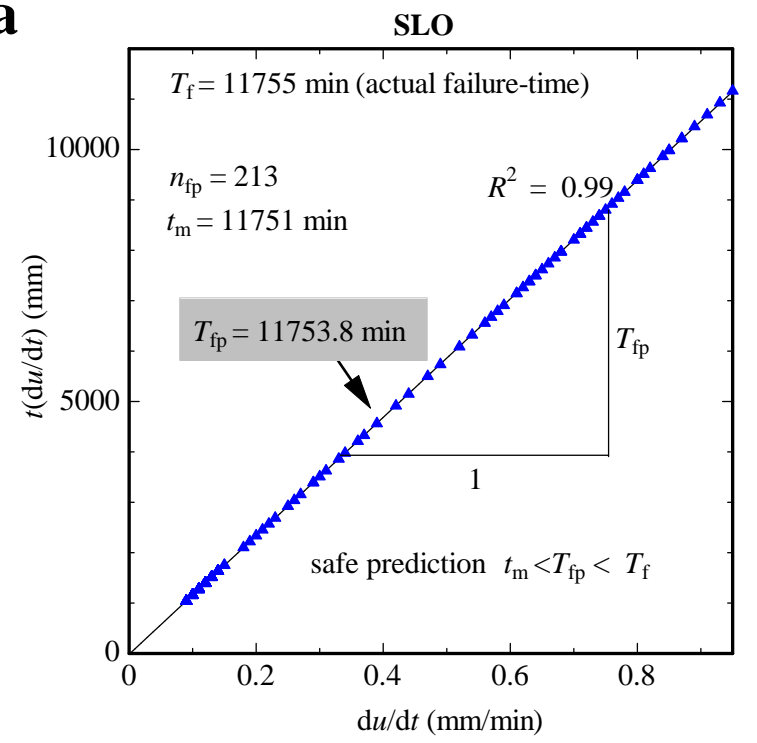

b

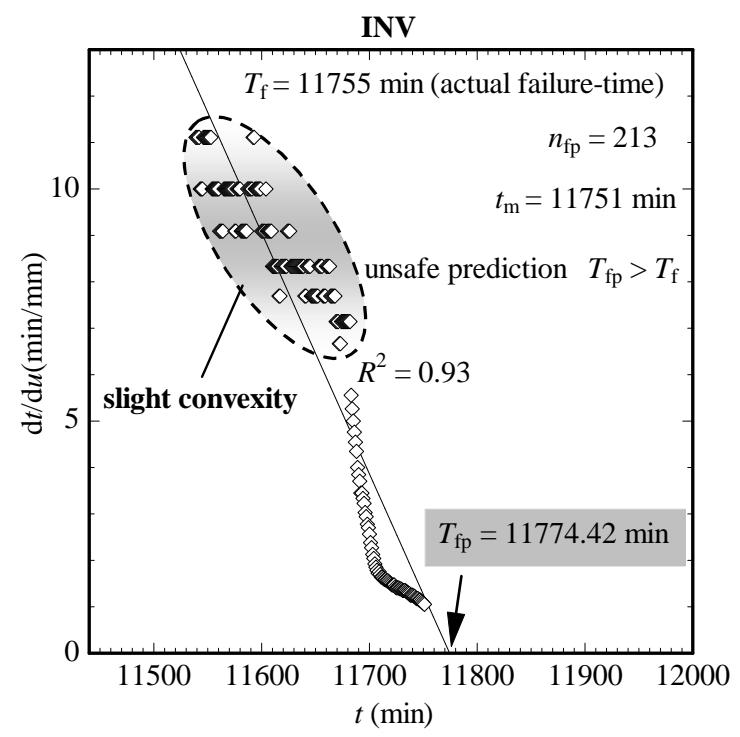

Fig. 8. Typical plots used for prediction of rock mass failure using (a) SLO and (b) INV methods

\subsubsection{Failure indicators}

From 550-650 days, displacement rate was approximately between $0.25-0.5 \mathrm{~cm} / \mathrm{day}$ and the velocity was gradually increasing toward failure $T_{\mathrm{f}}=700$ days (Fig. 7a), whilst inverse-velocity was approaching zero (Fig. 7b). At 50 days before failure (Fig. 7a), there was a steep increase in displacement rate, a critical velocity of $0.54 \mathrm{~cm} /$ day $(0.037$ $\mathrm{mm} / \mathrm{min}$ ); this was due to reservoir filling and precipitation in the form of heavy rains [11]. This increased pore pressure at the toe of the slope, hence resulting in failure. 
$\mathbf{a}$

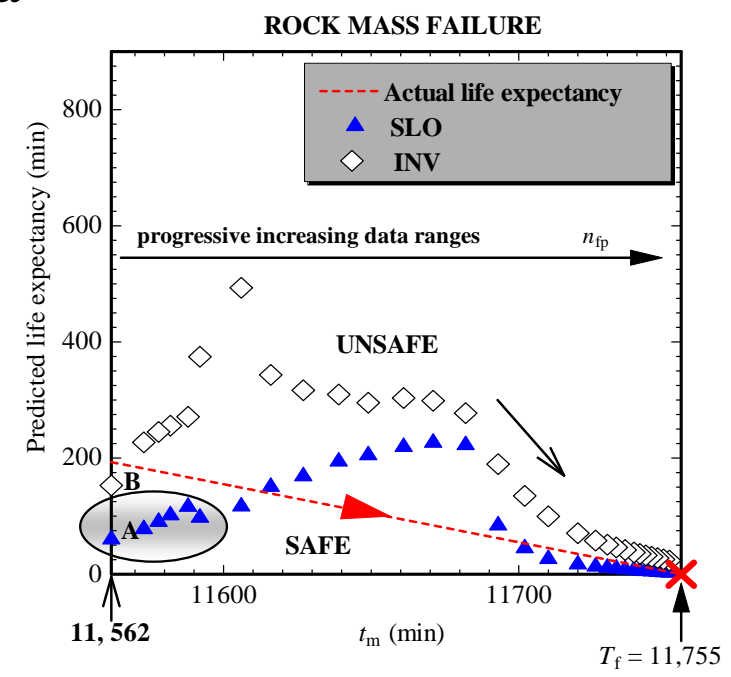

b

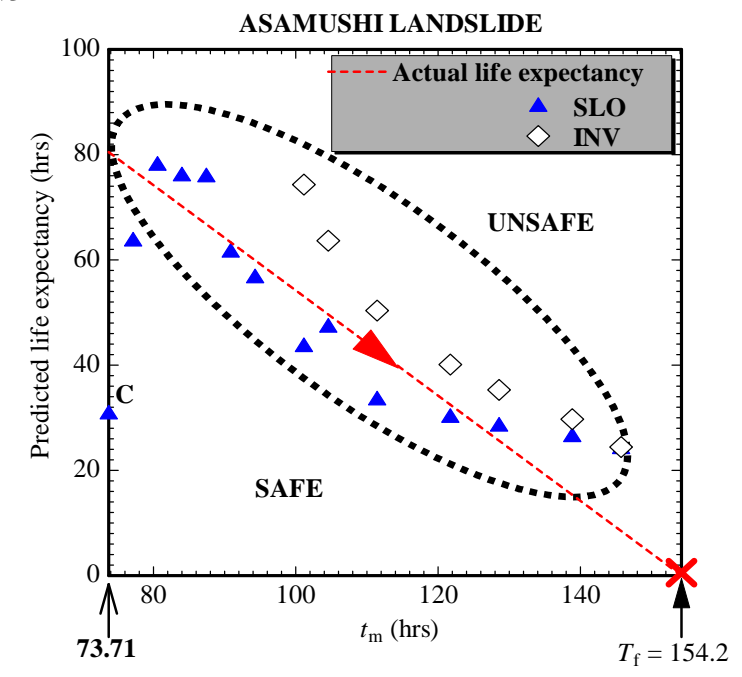

c

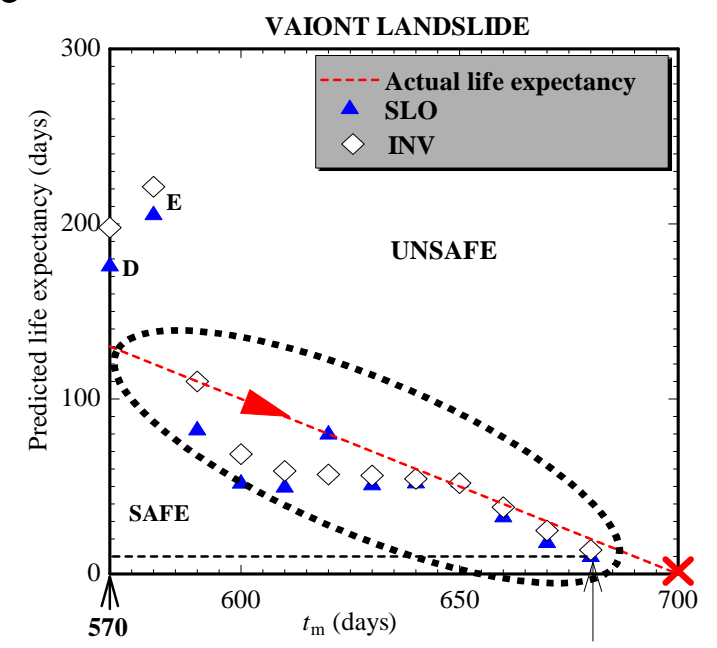

$t=680$ (20 days before failure)

Fig. 9. Predicted life expectancy as a function of time $t_{\mathrm{m}}$ from SLO and INV methods (a) Rock mass failure (b) Asamushi landslide (c) Vaiont landslide reservoir. Symbol $\times$ depicts "failure," and points A-E denote initial or early predictions.

\section{Prediction of Case Histories}

The issue of predictability of rock mass failure and landslides, which are major geo-hazards, is of great concern. And with complexity, not to mention the different precursory failure mechanisms, the sudden occurrence of landslides makes it difficult to forecast precisely [21,22]. However, with full view of these setbacks, attempts to predict failure-time of rock mass and landslides (Asamushi and Vaoint) based on recorded deformation data was done.

\subsection{Data sampling and criteria for predicting}

To explain our approach in forecasting geomechanical failure-time, we will utilize the deformation data from rock mass failure as an example (Fig. 4). Taking a closer look at Fig. $4 \mathrm{a}$ and $\mathrm{b}$, we can observe that after sampling data $(n=100$ in Eq. (5)), the onset of accelerating displacement rates is $t=$ 11,539 min. And at this point the corresponding number of data set is $n_{\mathrm{fp}}=1$, by simply counting (Fig. 4b). However, as the time $t$ increases towards actual failure-time $T_{\mathrm{f}}=11,755 \mathrm{~min}$, the number of data sets increases. For example, at $t=11,562$ and 11,751 min, the corresponding number of data sets is $n_{\mathrm{fp}}=$ 24 and 213 , respectively.

In reiteration, using observation and sound judgement, data set for initial prediction was selected by estimating the point where displacement rate progressively increased, and this corresponds to $n_{\mathrm{fp}}=24$ (Fig. $4 \mathrm{~b}$ ). Thereafter, during prediction, data sets were then gradually increased $\left(n_{\mathrm{fp}}=24, \ldots 213\right)$ until the period just prior failure $T_{\mathrm{f}}=11,755 \mathrm{~min}$.

After data sampling, SLO (newly proposed) and INV methods were then used in attempts to predict failure-time of rock mass failure.

Table 1

Summary of results of in situ failure-time predictions using SLO and INV

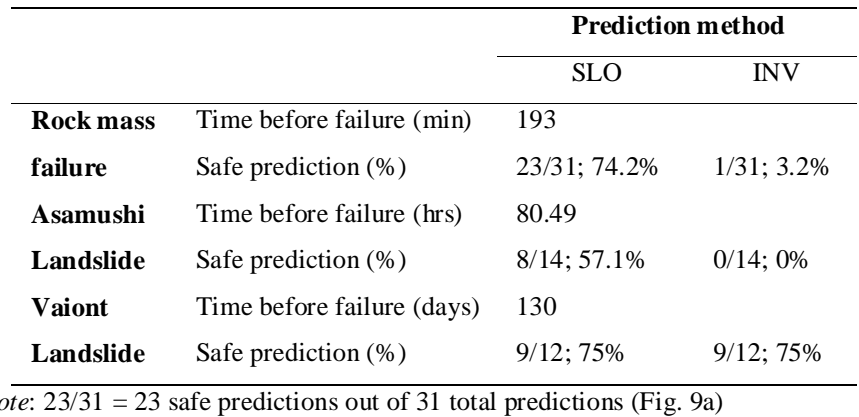


For illustration purposes, Figs. $8 \mathrm{a}$ and $\mathrm{b}$, shows typical prediction results using the SLO and INV method at $n_{\mathrm{fp}}=213$. Using SLO, $T_{\mathrm{fp}}$ was evaluated as the slope of $t(\mathrm{~d} u / \mathrm{d} t)-\mathrm{d} u / \mathrm{d} t$ curve (Fig. 8a). In a brief explanation, at $n_{\mathrm{fp}}=213$, corresponding to $t_{\mathrm{m}}=11,751 \mathrm{~min}$ (see, Fig. $4 \mathrm{~b}$ and Fig. 8), SLO gave a predicted failure-time, $T_{\mathrm{fp}}=11,753.8 \mathrm{~min}$, whilst actual failure-time $T_{\mathrm{f}}=11,755 \mathrm{~min}$ (safe prediction, $t_{\mathrm{m}}<T_{\mathrm{fp}}<$ $T_{\mathrm{f}}$, Fig. 8a). As a reminder, $t_{\mathrm{m}}$ is the time at each instant of predicting failure-time.

As for INV, $T_{\mathrm{fp}}$ was evaluated as the $x$-intercept of $(\mathrm{d} t / \mathrm{d} u-t)$ curve (Fig. 8b). Similarly, at $n_{\mathrm{fp}}=213$, INV gave $T_{\mathrm{fp}}=11,774$. 42 min (unsafe prediction, $T_{\mathrm{fp}}>T_{\mathrm{f}}$, Fig. 8b). This approach of arbitrarily assuming the onset of accelerating deformations prior failure, and use of progressive increasing data sets $n_{\mathrm{fp}}$ (towards failure) to compute predictions $T_{\mathrm{fp}}$ (using SLO and INV) was adopted in all the cases to follow.

\section{Interpretation of predictions from case histories}

Using the above-mentioned principles, prediction of rock mass failure that occurred in an open-pit limestone mine, Japan (2007) was done and, Fig. 9a shows predicted life expectancy against time $t_{\mathrm{m}}$ for rock mass failure. First and foremost, points A and B (Fig. 9a) denotes initial prediction $\left(n_{\mathrm{fp}}=24\right.$ at $t=t_{0}=$ 11,562 min, see Fig.4b), this means we could have managed to predict failure at $193 \min \left(T_{\mathrm{f}}-11,562\right)$ before failure $\left(T_{\mathrm{f}}=\right.$ $11,755 \mathrm{~min}$ ) using both methods. And this physically means there is time to evacuate in the case of a geo-hazard. More importantly, for SLO, 23 out of 31 were safe predictions (Fig. 9a), that is, $74.2 \%$ safe predictions (Table 1). Furthermore, small data ranges, that is, initial predictions (encircled data points, Fig. 9a) gave safe predictions.

On the other hand, for INV, 3.2\% (1 out of 31 predictions, Fig. 9a) were safe predictions (Table 1). Most predictions were unsafe (Fig. 9a); this could be due to the slight convex nature of inverse-velocity in the initial stages (Fig. 8b). Because of this convexity, the $x$-intercept $\left(T_{\mathrm{f}}\right)$ in INV depends much more on large inverse-velocities, that is, small velocities. This could explain why INV predictions approached $T_{\mathrm{f}}$ from the unsafe region. In contrast, in SLO, the slope $\left(T_{\mathrm{f}}\right)$ depends more on the large velocities. This explains why SLO gives better prediction although SLO and INV are based on the same equation. $\mathbf{a}$

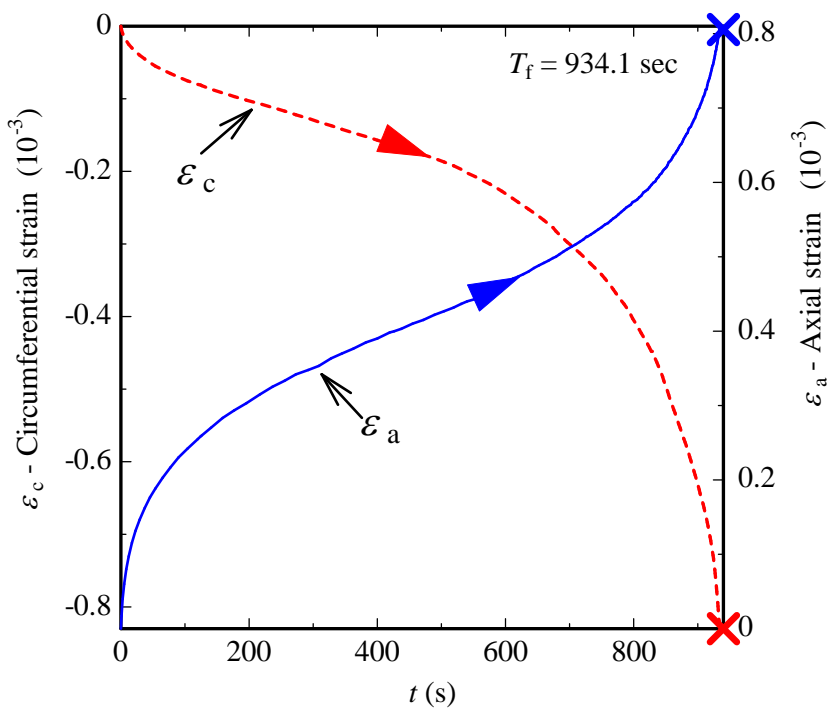

b

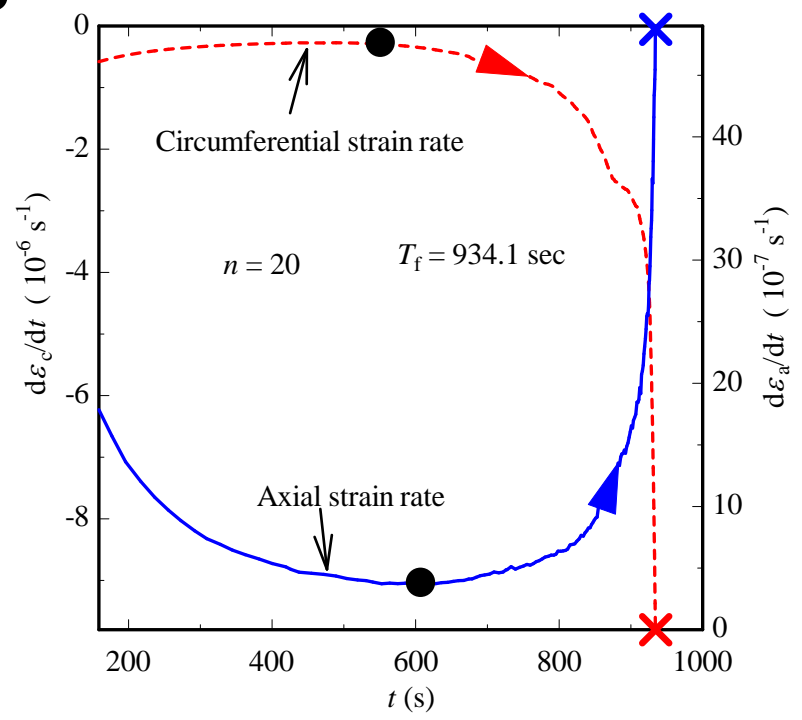

Fig. 10. (a) Variations of $\varepsilon_{\mathrm{c}}$ and $\varepsilon_{\mathrm{a}}$ at $\sigma_{1}=18.4 \mathrm{MPa}$, and (b) corresponding strain rates $\left(\mathrm{d} \varepsilon_{\mathrm{d}} / \mathrm{d} t\right)$ and $\left(\mathrm{d} \varepsilon_{\mathrm{a}} / \mathrm{d} t\right)$ against time $t$, for SWT using $n=20$ (158.6 sec) in Eq. (5). Symbol $\times$ denotes creep rupture $T_{\mathrm{f}}=934.1 \mathrm{sec}$, and symbol $\bullet$ denotes the assumed onset of accelerating creep.

Generally, predictions became more precise as failure-time was approached using both methods.

For Asamushi landslide, a similar procedure was repeated in analysis as described in Section 4.1, now only with $t=0 \mathrm{hrs}$, assumed to be the onset of accelerating creep (Fig. 5a). Data sets/ranges were progressively increased at the time of computing predictions (i.e., $n_{\mathrm{fp}}=13, \ldots 34$ ), almost to ranges just at failure (Fig. 5b). 
a

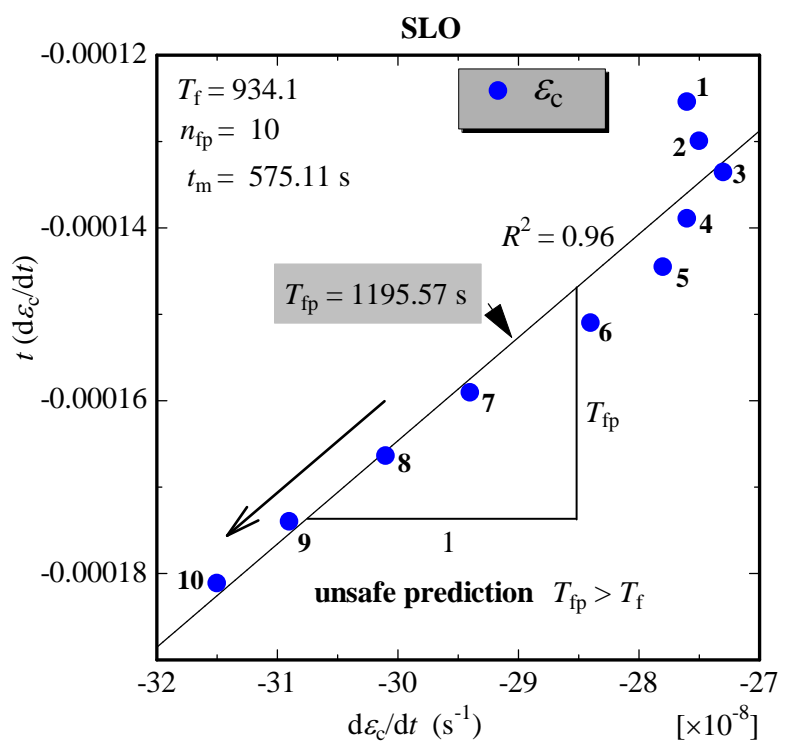

b

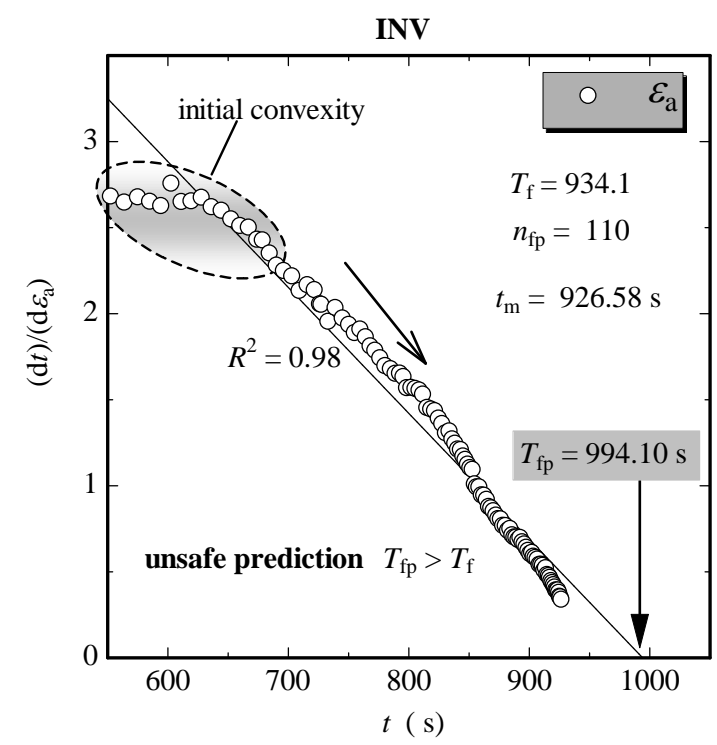

Fig. 11. Typical plots for failure-time prediction of SWT using (a) SLO under $\varepsilon_{\mathrm{c}}$ at $n_{\mathrm{fp}}=10$ corresponding to $t_{\mathrm{m}}=575.11 \mathrm{sec}$, and (b) INV under $\varepsilon_{\mathrm{a}}$ at $n_{\mathrm{fp}}=$ 110 corresponding to $t_{\mathrm{m}}=926.58 \mathrm{sec}$.

Fig. 9b shows predicted life expectancy against time for Asamushi landslide that occurred at $\left(T_{\mathrm{f}}=154.2 \mathrm{hrs}\right)$. For SLO, $57.1 \%$ (8 out of 14) were safe predictions (see, Table 1 and Fig. 9b). Point C (Fig. 9b) denotes initial prediction $\left(n_{\mathrm{fp}}=13\right.$ at $t=$ $t_{0}=73.71$ hrs, see Fig. 5b). This means we could have managed to predict failure at $80.49 \mathrm{hrs}\left(T_{\mathrm{f}}-73.71\right)$ before actual failure (Fig. 9b and Table 1).

Using INV, all predictions had unsafe errors, $0 \%$ safe predictions (Table 1), and initial predictions had the largest unsafe errors, this may be due to the convex nature of inverse-

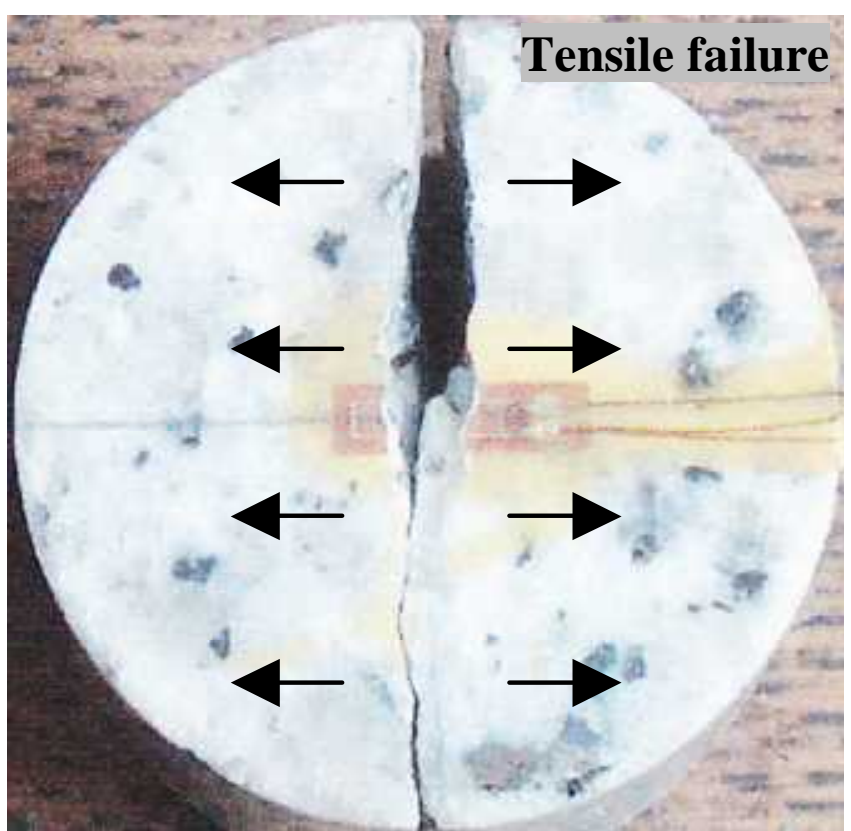

Fig. 12. Failure of Inada granite; splitting mode under tension.

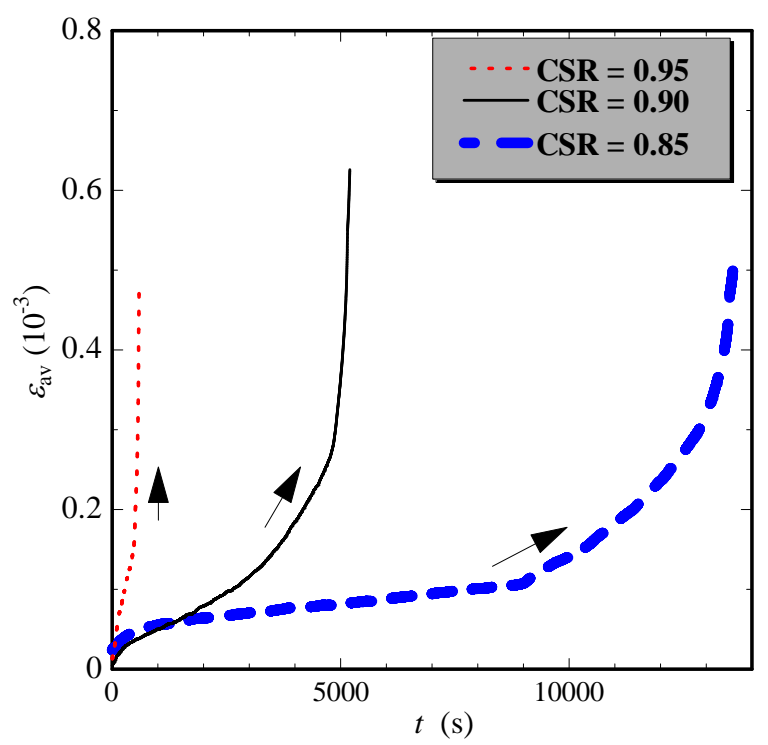

Fig. 13. Time-dependent behaviour of Inada granite under Brazilian creep tests, at different CSRs up to creep rupture.

velocity similar to the one in Fig. 8b. Furthermore, initial predicted life expectancies for INV are very large (Fig. 9b). However, with progressively increasing data ranges $n_{\mathrm{fp}}$ towards failure, predictions became more precise (Fig. 9b). Therefore, the landslide could be predicted using SLO, $80.49 \mathrm{hrs}$ before the failure (point C) with $50.49 \mathrm{hrs}$ of safe error (Fig. 9b). It is also interesting to note that, although all the two methods had $T_{\mathrm{fp}} \mathrm{s}$ scattered around the actual life expectancy curve $\left(T_{\mathrm{fp}}=T_{\mathrm{f}}\right)$, 
a

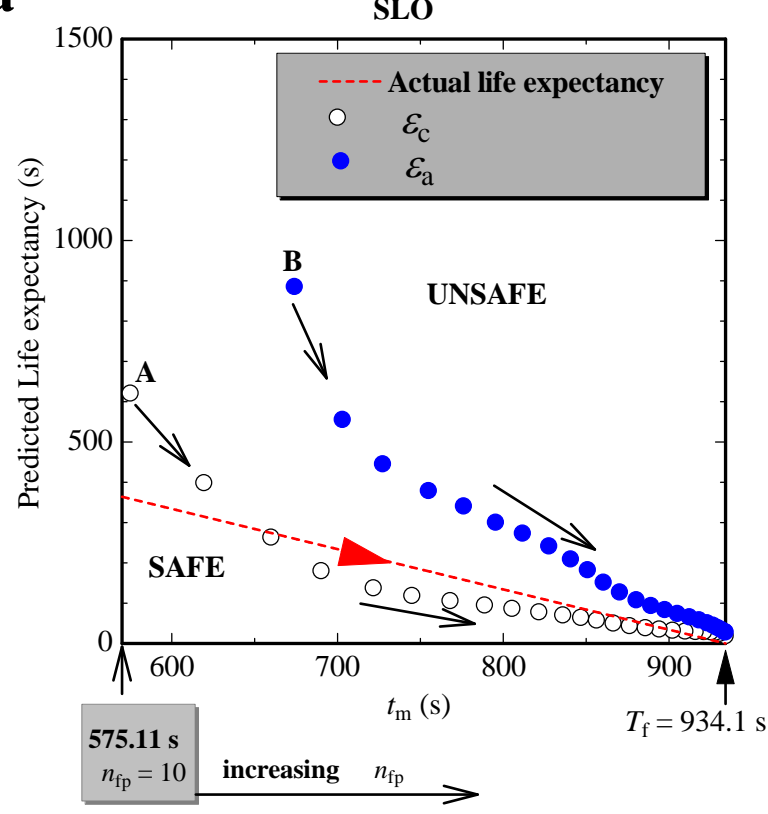

b

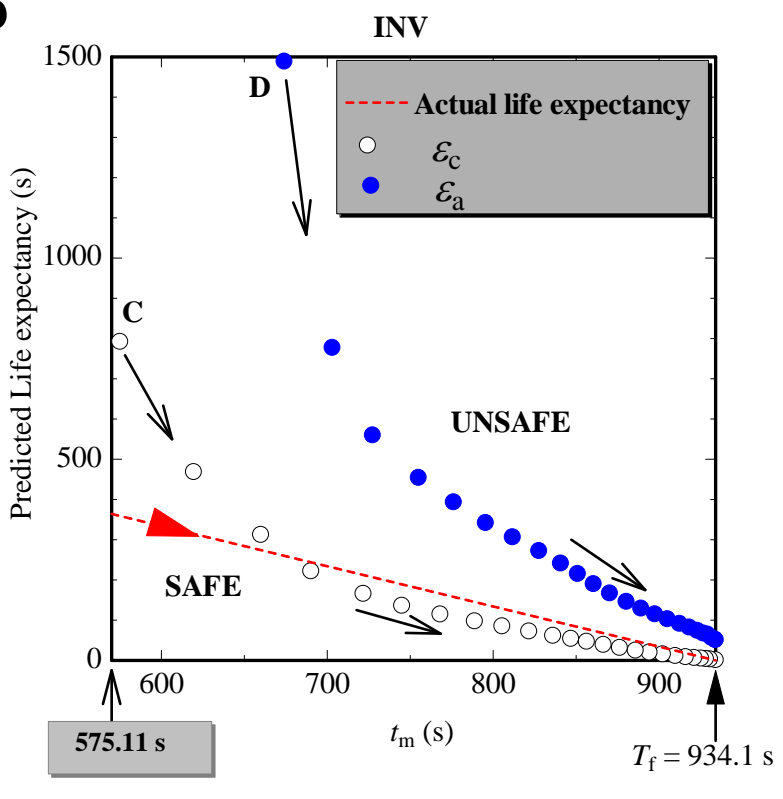

Fig. 14. Decreasing predicted life expectancy as a function of $t_{\mathrm{m}}$ from $\varepsilon_{\mathrm{c}}$ and $\varepsilon_{\mathrm{a}}$ using (a) SLO, and (b) INV methods. Points A-D denotes initial predictions.

Table 2

Summary of failure-time predictions using $\varepsilon_{\mathrm{c}}$ and $\varepsilon_{\mathrm{a}}$ for SWT

\begin{tabular}{cllc}
\hline & & \multicolumn{2}{c}{ Prediction method } \\
\cline { 3 - 4 } & & SLO & INV \\
\hline \multirow{2}{*}{$\varepsilon_{\mathrm{c}}$} & Time before failure (s) & 358.99 & \\
& Safe prediction (\%) & $15 / 25 ; 60 \%$ & $21 / 25 ; 84 \%$ \\
& Time before failure (s) & 259.99 & \\
\multirow{2}{*}{$\varepsilon_{\mathrm{a}}$} & Safe prediction (\%) & $0 / 25 ; 0 \%$ & $0 / 25 ; 0 \%$ \\
& & &
\end{tabular}

Note: $15 / 25=15$ safe predictions out of 25 total predictions (Fig. 14a)

SLO had majority of predictions more close or along the actual life expectancy path (Fig. 9b). These $T_{\mathrm{fp}} \mathrm{s}$ (encircled, Fig. 9b) could be used to extrapolate a reasonable $T_{\mathrm{f}}$ under linear fits.

Likewise, SLO and INV were used in attempts to predict failure-time $\left(T_{\mathrm{f}}=700 \mathrm{hrs}\right)$ for the Vaiont landslide, only now with $t=550$ days estimated as onset of accelerating creep (Fig. 7a), and the results are as shown in Fig. 9c.

Notably, both methods have predictions with a similar trend but with slight variations (Fig. 9c). Failure was predicted 130 days $\left(T_{\mathrm{f}}-570\right)$ before actual failure with point D having 45-68 days of unsafe error (Fig. 9c). In addition, both prediction methods (SLO and INV) gave a reliable estimation of $T_{\mathrm{f}}$, with both having $75 \%$ safe predictions (Table 1 ), that is, 9 out 12 safe predictions (Fig. 9c). For example, predicted life expectancy becomes less than 10 days on 20 days before failure using both methods (Fig. 9c). Government and responsible authorities should have adequate time to alert people to evacuate to safe places before the landslide. It is worth noting that small data ranges used to predict $T_{\mathrm{fp}}$ at points $\mathrm{D}$ and $\mathrm{E}$ (Fig. 9c) gave life expectancies that were in the unsafe error region that gradually shifted towards the safe error region as data range $n_{\mathrm{fp}}$ increased whilst $T_{\mathrm{f}}$ was approached. At points D and E, SLO has slightly smaller unsafe errors (Fig. 9c) compared to INV. With regard to predictions, a general trend can be observed, that is, $T_{\mathrm{fp}}$ became more precise to $T_{\mathrm{f}}$ as data range $n_{\mathrm{fp}}$ increased (Fig. 9c). It is also interesting to note that, both methods had $T_{\mathrm{fp}} \mathrm{s}$ scattered around the actual life expectancy curve $\left(T_{\mathrm{fp}}=T_{\mathrm{f}}\right)$, and most predictions were close or along the actual life expectancy path (Fig. 9c). In essence, these $T_{\mathrm{fp}} \mathrm{s}$ (encircled, Fig. 9c) could be used to extrapolate a reasonable $T_{\mathrm{f}}$ under linear fits.

\section{Experimental studies}

\subsection{Creep test on Shikotsu welded tuff}

Laboratory uniaxial compression creep tests were carried out on Shikotsu welded tuff (SWT) [23]. The tests were performed on SWT cylindrical specimens $(60 \mathrm{~mm}$ length, 30 mm diameter), which were oven-dried at $80^{\circ} \mathrm{C}$ for $24 \mathrm{hrs}$. The 
specimens were kept in the laboratory for several days at $21.5^{\circ} \mathrm{C}$ and then tested. Loading was carried out using an Instron 5586 loading frame $(300 \mathrm{kN})$ through spherical seating. In order to monitor strains, two displacement sensors, a cliptype and chain-type sensors were attached on the surface of the specimens to measure $\varepsilon_{\mathrm{a}}$ and $\varepsilon_{\mathrm{c}}$, respectively. The uniaxial compressive strength $\left(\sigma_{\mathrm{c}}=23.3 \mathrm{MPa}\right)$ for the SWT specimen was pre-measured so that the creep stress $\left(\sigma_{1}\right)$ could be reasonably selected. The rock specimens were uniaxially loaded under compression to creep stress $\left(\sigma_{1}\right)$ of 18.4 MPa, which was then kept constant during the creep tests until failure, and the results are as indicated in Fig. 10a. The strain variations show characteristic regions of creep in rock, from primary to tertiary creep. Reasonably, points of minimum strain rates were assumed to be the onset of accelerating creep (Fig. 10b). A closer look at Fig. 10b shows that circumferential strain rate approached tertiary creep earlier than axial strain rate but the difference is less significant. And finally, creep rupture $T_{\mathrm{f}}$ occurred at 934.1 seconds from the beginning of uniaxial compression creep test.

\subsubsection{Approach to predicting}

To compute predictions using circumferential strain $\left(\varepsilon_{\mathrm{c}}\right)$ and axial strain $\left(\varepsilon_{\mathrm{a}}\right)$, the same procedure for computing predictions was done as described in previous cases. For SLO, substituting $u$ by $\varepsilon_{\mathrm{c}}$ and $\varepsilon_{\mathrm{a}}$ in Eq. (3), $T_{\mathrm{fp}}$ is evaluated as the slope of of $t\left(\mathrm{~d} \varepsilon_{\mathrm{c}} / \mathrm{d} t\right)-\mathrm{d} \varepsilon_{\mathrm{c}} / \mathrm{d} t$ curve (Fig. 11a) and similarly as the slope of $t\left(\mathrm{~d} \varepsilon_{\mathrm{a}} / \mathrm{d} t\right)-\mathrm{d} \varepsilon_{\mathrm{a}} / \mathrm{d} t$ curve. In INV, substituting $u$ by $\varepsilon_{\mathrm{a}}$ and $\varepsilon_{\mathrm{c}}$ in Eq. (4), $T_{\mathrm{fp}}$ is evaluated as the $x$-intercepts of $\left(\mathrm{d} t / \mathrm{d} \varepsilon_{\mathrm{a}}-t\right)$ curve (Fig. $11 \mathrm{~b})$ and $\left(\mathrm{d} t / \mathrm{d} \varepsilon_{\mathrm{c}}-t\right)$ curve.

\subsection{Brazilian Creep test using Inada granite}

Laboratory Brazilian creep tests were carried out on dry Inada granite to explore the ability to predict extensile failuretime for rock specimens [24]. In the Brazilian creep tests, 30 $\mathrm{mm}$ long cylindrical dry specimens of diameter $30 \mathrm{~mm}$ from Inada granite were loaded in compression using an Instron 5586 loading frame $(300 \mathrm{kN})$. In order to monitor the corresponding tensile strains, two strain gauges $(5 \mathrm{~mm}$ gauge length) were attached on both ends of each rock specimen on its horizontal diametrical planes. The Brazilian tensile strength $\left(\sigma_{\mathrm{t}}=6.98 \mathrm{MPa}\right)$ for Inada granite specimens was predetermined so that the creep stress ratios (CSR) could be reasonably selected, hence resulting in failure. Three sets of experiments were run on CSRs (i.e., 0.85, 0.90 and 0.95), and kept constant throughout the creep test. Post-failure inspection of the Inada granite specimens exhibits splitting along their diametrical planes parallel to the loading axis (Fig. 12).

Mean strain $\left(\varepsilon_{\mathrm{av}}\right)$ was calculated from the extensile strains from the two horizontal diametrical planes and then movingaveraged to remove noise (Fig. 13). This strain $\left(\varepsilon_{\mathrm{av}}\right)$ was later used in computing predictions $T_{\mathrm{fp}} \mathrm{s}$. Fig. 13, shows characteristic curves of creep in rocks until failure. High CSR (0.95) resulted in short time to failure and vice-versa. Strain rates were calculated using Eq. (5), and points of minimum strain rates were assumed to mark the onset of accelerating creep, and thereafter, prediction was done using SLO and INV.

\section{Experimental results}

Shikotsu welded tuff: Fig. 14 shows results of predicted life expectancy as a function of time $t_{\mathrm{m}}$ for Shikotsu welded tuff using circumferential strain $\left(\varepsilon_{\mathrm{c}}\right)$ and axial strain $\left(\varepsilon_{\mathrm{a}}\right)$ from SLO and INV methods. Predictions of failure-time for SWT using circumferential strain $\varepsilon_{\mathrm{c}}$ by SLO method were conducted under progressively increasing data ranges (i.e., $n_{\mathrm{fp}}=10, \ldots 133$ ) until the period just prior failure $T_{\mathrm{f}}=934.1 \mathrm{sec}$. To begin with, point A (Fig. 14a), shows initial predicted life expectancy using $n_{\mathrm{fp}}=$ 10 (Fig. 11a). This point lies in the unsafe region $\left(T_{\mathrm{fp}}>T_{\mathrm{f}}\right)$; however, it serves as an early warning signalling imminent failure. Hence, at this point (A), failure was predicted 358.99 sec before occurrence $\left(T_{\mathrm{f}}-575.11\right)$. From point A onwards, we can observe that predicted life expectancy gradually decreased towards zero, at failure. Furthermore, 15 out of 25 of the $\varepsilon_{\mathrm{c}}$ predictions (60\%) had safe errors (Fig. 14a and Table 2).

On the other hand, SLO using $\varepsilon_{\mathrm{a}}$ predicted failure at 259.99 sec (at point $\mathrm{B}, t_{\mathrm{m}}=t_{0}=674.11 \mathrm{~s}$ ) before $T_{\mathrm{f}}$. Initially, small data ranges gave large predicted life expectancies (point B in Fig. 14a). This may possibly be due to low strain rates at the onset of tertiary creep (Fig. 10b). All predictions had unsafe errors ( 0 out of $25 ; 0 \%$ safe predictions (see $\varepsilon_{\mathrm{a}}$, Fig. 14a and 
$\mathbf{a}$

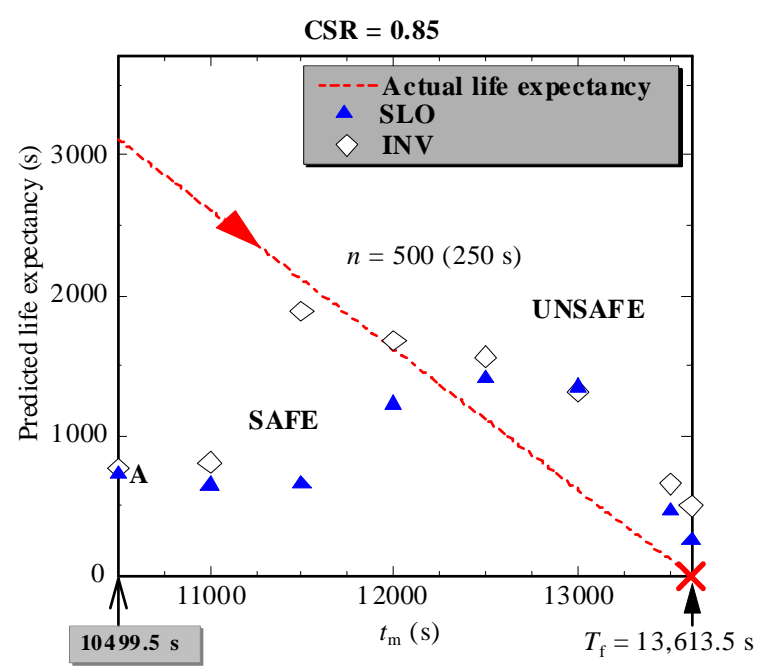

b

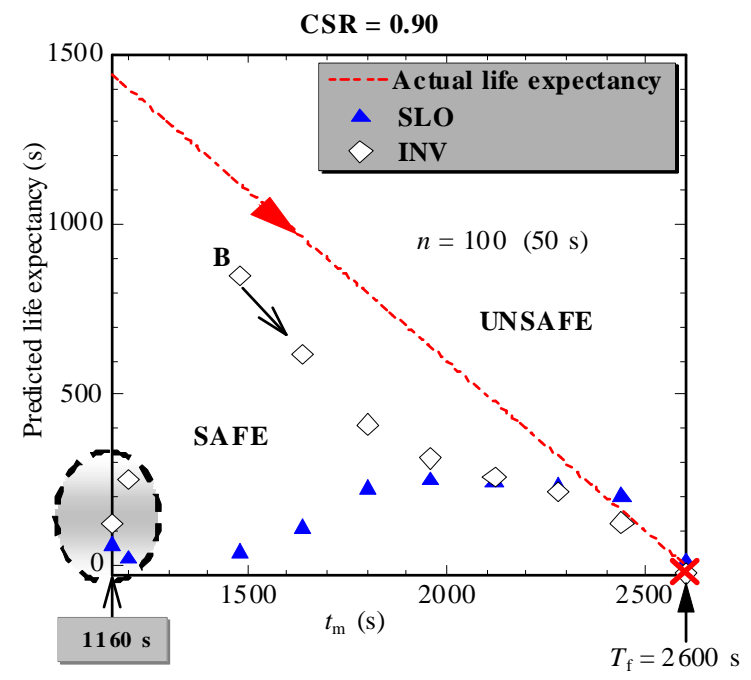

c

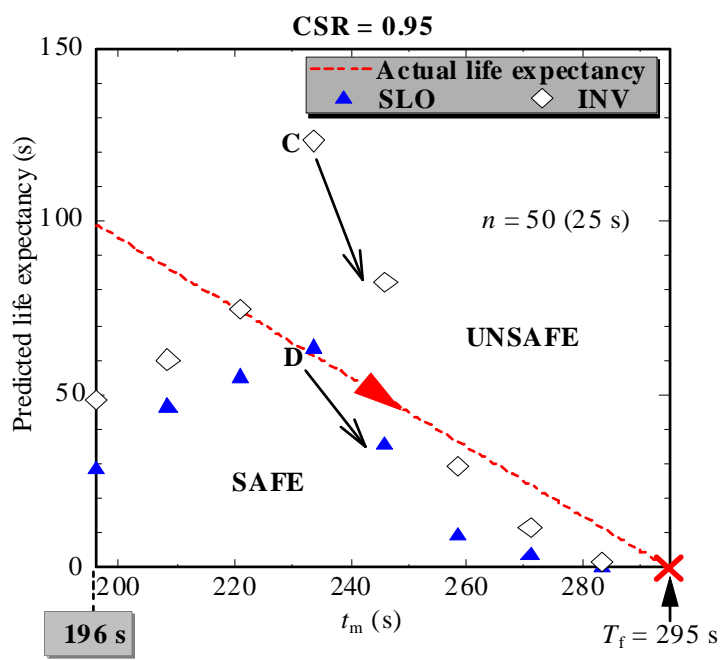

Fig. 15. Predicted life expectancy as a function of $t_{\mathrm{m}}$ for Inada granite using SLO and INV at CSRs (a) 0.85 (b) 0.90 (c) 0.95 . Symbol $\times$ depicts "failure," and $n$ is used in Eq. (5) to filter data at a selected intervals.
Table 2). Nevertheless, predicted life expectancy gradually decreased as $T_{\mathrm{f}}$ approached ( $\varepsilon_{\mathrm{a}}$, Fig. 14a); and notably, point A $\left(\varepsilon_{c}\right)$ is earlier than point $\mathrm{B}\left(\varepsilon_{\mathrm{a}}\right)$ as shown in Fig. 14a.

In a similar manner, INV was used to predict $T_{\mathrm{f}}$ using $\varepsilon_{\mathrm{c}}$ and point C (Fig. 14b), denotes initial prediction at $t_{\mathrm{m}}=t_{0}=$ $575.11 \mathrm{sec}$. And as mentioned before, this means we could have managed to predict failure at $358.99 \mathrm{sec}$ before $T_{\mathrm{f}}$ at $84 \%$ (21/25) safe predictions (Table 2 and Fig. 14b). On the other hand, using $\varepsilon_{\mathrm{a}}$, point $\mathrm{D}$ (Fig. 14b) denotes initial prediction $t_{0}=$ 674.11 sec. As in point $B$, this implies that failure could be predicted at $259.99 \mathrm{sec}$ before occurrence, and all predictions had unsafe errors ( $\varepsilon_{\mathrm{a}}$, Fig. 14b); 0\% (0/25) safe predictions (see, Table 2). Additionally, initial small data ranges gave large predicted life expectancies (Fig. 14b). This may possibly be due to the convex nature of the inverse-velocity at the onset of tertiary creep (encircled data points, Fig. 11b).

From observation, it can be deduced that predictions using $\varepsilon_{\mathrm{c}}$ had greater reliability (safe predictions) than predictions using $\varepsilon_{\mathrm{a}}$ (unsafe predictions) as revealed in Fig. 14. Generally speaking, despite the safe and unsafe errors in both methods, predictions followed a nearly consistent concave path towards failure (Fig. 14).

Inada granite: Fig. 15 shows results of predicted life expectancy against time $t_{\mathrm{m}}$ for Inada granite, computed from SLO and INV at different creep stress ratios (i.e., 0.85, 0.90 and 0.95). At CSR $=0.85$, creep test lasted for 13,613.5 $\sec \left(T_{\mathrm{f}}\right)$ as illustrated in Fig. 15a. Point A denotes initial predictions, which could be done at $3114 \mathrm{sec}\left(T_{\mathrm{f}}-10499.5\right)$ before failure using both methods SLO and INV, respectively (Fig. 15a). SLO and INV had 50\% (4/8) and 37.5\% (3/8) safe predictions, respectively (Fig. 15a and Table 3); but moved from safe to unsafe region towards failure (Fig. 15a).

At CSR $=0.90$, creep test lasted for $2600 \mathrm{sec}$ (Fig. 15b). Both methods had small initial predicted life expectancy (see dotted circle in Fig. 15b); these data points signal imminent failure. SLO had $80 \%$ (8/10) safe predictions, and predictions could be done at $1440 \mathrm{sec}$ before failure using both methods SLO and INV, respectively (Fig. 15b and Table 3). Predictions using SLO followed an irregular path-this makes forecasting of $T_{\mathrm{f}}$ limited. As a positive outcome, both methods had most 
predictions in the safe region (Fig. 15b), and INV had $100 \%$ (10/10) safe predictions. At Point B (INV) in Fig. 15b, $t_{\mathrm{m}}=$ $1480 \mathrm{sec}$ (1120 sec before failure); it can be observed that predictions followed a roughly linear path towards failurethis is good in extrapolating future $T_{\mathrm{f}}$.

Lastly, at CSR $=0.95$, creep test lasted for $295 \mathrm{sec}$ (Fig. 15c). Both methods SLO and INV had the majority of predictions in the safe region, $87.5 \%(7 / 8)$ and $62.5 \%(5 / 8)$, respectively; and initial predictions could be done at $99 \mathrm{sec}$ before failure (Fig. 15c and Table 3). At Points C and D (Fig.15c), corresponding to $t_{\mathrm{m}}=233.5 \mathrm{sec}$ (61.5 sec before failure), which are ranges close to failure-both methods abruptly approached failure.

The general focus of this research is to attempt to predict failure-time under accelerating deformations prior to failure. But given the dominant brittle tensile failure of Inada granite, it can be observed that there is a small-medium tertiary region in the three creep curves (Fig. 13). Logically, it is difficult if not impossible, to prepare for imminent failure that is sudden and dominantly brittle in nature $[25,26]$. Under the three CSRs, SLO had predictions that followed an irregular path, though predictions gradually approached $T_{\mathrm{f}}$ (Fig. 15). It can be deduced that given the dominant brittle tensile failure of the small Inada granite specimens (Fig. 15), the methods seem to have limited reliability.

\section{Discussion}

A challenging task to predict geomechanical failure-time of geo-hazards has been conducted. The SLO and INV methods were proposed in attempts to predict geomechanical failuretime in situ and in experimental studies.

\subsection{Time effects, scale effects and failure mechanisms}

Both methods, particularly SLO, were applicable (safe predictions) under different time scales, from seconds in SWT, minutes in rock mass failure, hours in Asamushi landslide, and lastly, days in Vaiont landslide (Fig. 9 and 14) [27].

Prediction results also revealed scale-independency of SLO and INV in predicting failure-time across the spectrum, from small scale laboratory creep tests to real-life large failures, such as the $500 \mathrm{~m}^{3}$ of rock mass failure, $100,000 \mathrm{~m}^{3}$ for Asamushi landslide and the 270 million $\mathrm{m}^{3}$ for Vaiont landslide. We view this as a positive development on the rock mechanics side in our ongoing efforts to develop prediction methodologies that can adapt to different sizes of failure. In essence, we have also noted that the methods seem useful under different failure modes. In rock mass failure, which was largely dominated by structural failure (rupture plane, Fig. 2), we obtained safe predictions (Fig. 9a). We also obtained good predictions on the landslides (Asamushi and Vaiont). Furthermore, under compression and tensile creeping mechanisms (Brazilian creep test and uniaxial compression creep test), safe predictions were observed (Fig. 9c, $\varepsilon_{\mathrm{c}}$ in Fig. 14 and Fig. 15). Also to mention, predicted cases in this study were composed of different rocks, namely limestone in rock mass failure, (limestone, shale, and clay) in Vaiont landslide, (liparitic tuff) in Asamushi landslide, and Shikotsu welded tuff. However, for Inada granite, (dominantly brittle in nature), the methods tend to show limited reliability. Though the methods have predictive capability in different rock types, there is still a necessity to improve these methods over a wide range of rocks type, sizes and different sorts of failure.

\subsection{Deformation rates}

We appreciate that rocks are complex heterogeneous materials, and this quality affects their intrinsic deformation nature [27,28]. However, in this study, under different progressively increasing deformation rates from different rock types (Figs. 4b, 5b, 7a, and 10b), we found that, because of the typical initial convexity in the inverse-velocity plot (Figs. 8b and $11 \mathrm{~b})$, the $x$-intercept $\left(T_{\mathrm{f}}\right)$ in INV depends much more on large inverse-velocities, that is, small velocities. Thus why INV predictions initially or approached $T_{\mathrm{f}}$ from the unsafe region (Fig. 9 and 14). Contrary, in SLO, the slope $\left(T_{\mathrm{f}}\right)$ depends more on the large velocities. And in general, increasing deformation rates increases the likelihood of safe predictions (Fig. 9b and c, Fig. 14). This explains why SLO gives better prediction (safe prediction) although SLO and INV are based on the same equation. Qualitatively, in both methods, predictions became more precise as failure-time $\left(T_{\mathrm{f}}\right)$ approaches. 
Table 3

Summary of failure-time predictions for Inada granite from Brazilian creep tests

\begin{tabular}{llll}
\hline & & \multicolumn{2}{c}{ Prediction method } \\
CLOep stress ratio & \multicolumn{2}{c}{ INV } \\
\hline \multirow{2}{*}{0.85} & Time before failure (s) & 3114 & \multicolumn{1}{c}{$3 / 8 ; 37.5 \%$} \\
& Safe prediction (\%) & $4 / 8 ; 50 \%$ & \\
\multirow{2}{*}{0.90} & Time before failure (s) & 1440 & $10 / 10 ; 100 \%$ \\
& Safe prediction (\%) & $8 / 10 ; 80 \%$ & \\
\multirow{2}{*}{0.95} & Time before failure (s) & 99 & $5 / 8 ; 62.5 \%$ \\
& Safe prediction (\%) & $7 / 8 ; 87.5 \%$ & \\
\hline
\end{tabular}

\section{Concluding remarks}

Geo-hazards are still a major threat to life and a major loss in terms of economics in the geotechnical field. Since it is impossible to completely eliminate "failure," failure-time prediction methods are needed to mitigate the losses, that is, fatalities and damage to property. Therefore, attempts to predict failure-time $T_{\mathrm{f}}$ of rock mass failure, Asamushi landslide, Vaiont reservoir landslide, Shikotsu welded tuff (SWT), and Inada granite were done. Monitored displacements or strains were used to compute $T_{\mathrm{fp}}$ using SLO and INV methods. Predicted life expectancies from both methods were compared focusing mainly on the safe and unsafe errors. It is concluded that:

(1) Our new SLO gave much safer predictions in all the case studies.

(2) Conventional INV method gave initial unsafe predictions in most cases. This is possibly due to the initial convex nature of the INV plots. It tends to become more precise and linear, at ranges close to failure. This may rather be late to prepare for evacuation or plan for imminent "failure."

(3) As the size of data range $\left(n_{\mathrm{fp}}\right)$ increases, values of $T_{\mathrm{fp}}$ gradually converge to $T_{\mathrm{f}}$.

(4) Circumferential strain $\varepsilon_{\mathrm{c}}$ gave earlier and safer predictions than predictions using axial strain $\varepsilon_{\mathrm{a}}$ for SWT.

(5) Predictions from SLO using $\varepsilon_{\mathrm{c}}$ were the best in prediction of failure-time for SWT.

(6) Given the dominant brittle tensile failure of the small Inada granite specimens, the prediction methods seem to have limited reliability.

The SLO method developed and investigated in this research is a reliable predictive tool that proved consistent and was validated in most cases. SLO seems indispensable for different time scales from seconds in SWT, minutes in rock mass failure, hours in Asamushi landslide, and lastly, days in Vaiont landslide. Most importantly, SLO also proved useful under different scales of failure from small scale laboratory creep tests to real-life large failures, such as the $500 \mathrm{~m}^{3}$ of rock mass failure, $100,000 \mathrm{~m}^{3}$ for Asamushi landslide and the 270 million $\mathrm{m}^{3}$ for Vaiont reservoir landslide. Positively, it is a simple and quick method that can find use in planning and disaster management in the geotechnical field and in predicting other phenomena. These may include crack movements, landslides, rock mass and rock slope failures. However, our findings suggests that, given the variable nature of rock masses, there may be cases in which the methods described in this research fail to give reasonable prediction of failure-time, mostly in failures with very short tertiary creep. Furthermore, we acknowledge that it is a challenge to date, to develop a method that fits all rock types in all states of stress and failure under various conditions and time. For this reason, we recommend that the use of SLO method should also be combined with somewhat extensive practical experience and applied if possible with site-specific considerations. Although decisions to give early warning signals are based on initial or early predictions, this should be approved of a gradually decreasing predicted life expectancy towards failure.

Needless to mention, monitoring must be continued until failure and the results constantly, consistently re-evaluated and updated, to look for possible indicators of imminent failures. We are of the opinion that the methods described in this research should serve as guidance and are not a panacea for prediction of geomechanical failure-time. Therefore, pragmatically, they should be used to alert personnel on impending "failures." Since SLO is promising, ongoing efforts are devoted to improve the predictive capability of this method.

\section{Acknowledgements}

The authors would like to thank Mr. E. Nishiyama for his valuable reviews in this paper. 


\section{References}

[1] Bhandari RK. Some lessons in the investigation and field monitoring of landslides. In: 5th Int. Symp. Landslides, Bonnard, ed. Lausanne: Balkema, 1988, pp. 1453-1457.

[2] Saito M, Uezawa H. Failure of soil due to creep. In: Proceedings of the fifth Int. Conf. Soil Mech. Found. Eng., Montreal, 1961, pp. 315-318.

[3] Saito M. Forecasting time of occurrence of a slope failure. In: Proceedings of the sixth Int. Conf. Soil Mech. Found. Eng., ed. Oxford: Pergamon Press, 1965, pp. 537-541.

[4] Saito M. Forecasting time of slope failure by tertiary creep. In: Proceedings of the seventh Int. Conf. Soil Mech. Found. Eng., Mexico City, 1969, pp. 677-683.

[5] Zvelebil J, Moser M. Monitored based time-prediction of rock falls: Three Case Histories. Phys. Chem. Earth 2001; 26:159-167.

[6] Voight B. A method for prediction of volcanic eruption. Nature 1988; 332:125-130.

[7] Voight B. A relation to describe rate-dependent material failure. Science 1989; 243:200-203.

[8] Crosta GB, Agliardi F. Failure forecast for large rock slides by surface displacement measurements. Can. Geotech. J. 2003; 40:176-191.

[9] Cruden DM, Masoumzadeh S. Accelerating creep of the slopes of a coal mine. Rock Mechanics and Rock Engineering 1987; 20:123-135.

[10] Fukuzono T. A new method for predicting the failure time of a slope. In: Proceedings of the fourth international conference and field workshop on landslides. Tokyo: Japan Landslide Society, 1985, pp. 145-150.

[11] Rose ND, Hungr O. Forecasting potential rock slope failure in open pit mines using the inverse-velocity method. Int J Rock Mech Min Sci 2007; 44:308-320.

[12] Fujii Y, Kiyama T, Ishijima Y, Kodama J. Circumferential strain behavior during creep tests of brittle rocks. Int J Rock Mech Min Sci 1999; 36:323-337.

[13] Wyllie DC, Munn FJ. The use of movement monitoring to minimize production losses due to pit slope failures. In: Proceedings of the first international symposium on stability in coal mining. Vancouver, BC; Miller Freeman San Francisco, 1979, pp. 75-94.
[14] MacRae AMR. Case histories of deformation measurements in Canadian surface mines. In: Proceedings fourth Canadian Symposium on Mining, Surveying and Deformation Measurements. Canadian Institute of Surveying, Ottawa; 1982, pp. 255-278.

[15] Zavodni ZM, Broadbent CD. Slope failure kinematics. Canadian Institute of Mining Bull 1980; 99:69-74.

[16] Fukui K, Okubo S. Life expectancy and tertiary creep for rock. In: Proceedings of fall meeting of mining and materials processing institute of Japan, 1997. pp. 91-94 [in Japanese].

[17] Takahashi T, Makuuchi A, Nishiyama E, Yoshizawa H. Investigation of buried in limestone face. In: Proceedings of MMIJ fall meeting, 2006. pp. 17-20 [in Japanese].

[18] Vutukuri VS, Katsuyama K. Introduction to Rock Mechanics. Tokyo: Industrial Publishing and Consulting Inc., 1994.

[19] Genevois R, Ghirotti M. The 1963 Vaiont Landslide. Giornale di Geologia Applicata 1, 2005. pp. 41-52.

[20] Hoek E. Practical Rock Engineering. The development of rock engineering. In: <http://www.rocscience.com/hoek/PracticalRockEngineering.a sp>, 2007, pp. 1-4.

[21] Stef PS. Crack extension under compressive loading. Eng Fracture Mech 1984; 20(3):463-73.

[22] Atkinson BK. Subcritical crack growth in geological materials. J Geophys Res 1984; 89:4077-114.

[23] Ma L, Daemen JJK. An experimental study on creep of welded tuff. Int J Rock Mech Min Sci 2006; 43:282-291.

[24] Fujii Y, Takemura T, Takahashi M, Lin W. Surface features of uniaxial tensile fractures and their relation to rock anisotropy in Inada granite. Int J Rock Mech Min Sci 2007; 44:98-107.

[25] Hoek E. Brittle failure of rocks: Rock mechanics in engineering practice. In Stagg KG and Zienkiewicz OC, ed. London: Wiley J and Sons, 1968, pp. 99-124.

[26] Hajiabdolmajid V, Kaiser PK, Martin CD. Modelling brittle failure of rock. Int J Rock Mech Min Sci 2002; 39:731741.

[27] Cristescu ND, Hunsche U. Time effects in rock mechanics. England: Wiley, 1998.

[28] Cristescu ND. Rock rheology. Kluwer Academic, 1989. 